\title{
O TRABALHO INFANTIL E A NECESSÁRIA IMPLEMENTAÇÃO DE LIBERDADES SUBSTANTIVAS: UM ESTUDO SOBRE A EXTRAÇÃ̃ DO AÇAÍ NA ILHA DE MARAJÓ
}

\author{
Otávio Bruno da Silva Ferreira ${ }^{1}$ \\ Valena $\mathbf{J a c o b}^{2}$
}

\section{RESUMO}

$\mathrm{O}$ trabalho infantil priva a criança de liberdades substantivas. O estudo pretende identificar quais capacidades substantivas devem ser implementadas para a eliminação do trabalho infantil na cadeia produtiva do açaí na Ilha de Marajó. Para tanto, objetiva identificar os instrumentos para a eliminação dos fatores de indução e manutenção da ocorrência do trabalho infantil, por meio da apresentação de sua ocorrência na extração do açaí, da identificação dos fatores de risco para sua indução e permanência e da exposição sobre capacidades e funcionamentos. A partir de pesquisa qualitativa, aplicada, exploratória e bibliográfica, apresentam-se capacidades, com instrumentos e estratégias para solução.

PALAVRAS-CHAVE: Capacidades. Extração do Açaí. Funcionamentos. Trabalho Infantil. Desenvolvimento.

\section{CHILD LABOR AND THE NECESSARY IMPLEMENTATION OF SUBSTANTIVE CAPABILITIES: A STUDY ON THE EXTRACTION OF AÇAÍ IN THE ISLAND OF MARAJÓ}

\section{ABSTRACT}

Child labor deprives the child of substantive capabilities. The study intends to identify which substantive capabilities must be implemented for the elimination of child labor in the açaí production chain. To this end, it aims to identify the instruments for the elimination of factors that induce and maintain the occurrence of child labor, through the presentation of their occurrence in the extraction of açaí, the identification of risk factors for its induction and permanence, and the exposure on capabilities and workings. Based on qualitative, applied, exploratory and bibliographic research, capabilities are presented, with instruments and strategies to solving.

KEYWORDS: Capabilities. Extraction of Açaí. Runs. Child labor. Development.

\section{INTRODUÇÃO}

1 Mestre em Direito, Políticas Públicas e Desenvolvimento Regional pelo Centro Universitário do Estado do Pará - CESUPA. Professor da Graduação no Centro Universitário FIBRA. Professor convidado do Programa de Pós-Graduação Lato Sensu do Centro Universitário FIBRA e do Centro Universitário do Estado do Pará -

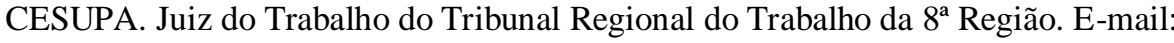
otavio.ferreira@trt8.jus.br

2 Doutora e Mestre em Direito pela UFPA. Professora da Graduação e do Programa de Pós-Graduação em Direito da UFPA; Diretora Geral do Instituto de Ciências Jurídicas da UFPA. Pesquisadora da Clínica de Direitos Humanos da Amazônia/UFPA. Líder do Grupo de Pesquisa CNPQ: Novas formas de trabalho, velhas práticas escravistas (dgp.cnpq.br/dgp/espelhogrupo/5232633034974997). Diretora da Escola Judicial da Associação Brasileira de Advogados Trabalhistas - ABRAT e Diretora da Associação Luso Brasileira de Juristas do Trabalho - JUTRA. e-mail: valenajacob@ufpa.br 
A criança goza de proteção com prioridade absoluta, em respeito à sua condição de pessoa em desenvolvimento ${ }^{3}$. Do conteúdo dos diplomas pátrios, extrai-se que o trabalho infantil é aquele realizado por crianças com idade inferior à mínima permitida para a entrada no mercado de trabalho, que, no Brasil, corresponde a 16 anos, salvo na condição de aprendiz, caso em que poderá ocorrer a partir dos 14 anos, com exclusão dos casos de trabalho noturno, perigoso ou insalubre, para os quais a idade mínima é 18 anos.

Segundo a Pesquisa Nacional por Amostra de Domicílios Contínua - PNAD Contínua (2016), no Brasil, havia 1,8 milhões de crianças e adolescentes de 5 a 17 anos em situação de trabalho infantil, na semana de referência da pesquisa, o que representava $4,6 \%$ da população (40,1 milhões) nesta faixa etária. Ou seja, a despeito da proteção normativa, há persistência do trabalho infantil na sociedade brasileira.

O trabalho infantil é fenômeno estrutural e complexo com origem em fatores multidimensionais, o que, portanto, exige que seja observado de forma holística. A identificação dos fatores de indução e permanência do trabalho infantil permite comprender o problema de forma integral e adotar medidas concretas para a sua erradicação, vez que a existência de diplomas normativos não tem se mostrado suficiente para atingir o objetivo de eliminá-lo.

Esse problema atinge atividades extrativas tradicionais na Amazônia, como a de coleta do açaí, fruto da palmeira conhecida como açaizeiro (Euterpe oleracea), que faz parte da cultura local e que, devido a alteração do modo de produção, determinou o envolvimento prematuro da criança na atividade de extração do fruto.

A partir do cenário exposto, especialmente a insuficiência dos diplomas normativos, o presente trabalho procura responder a seguinte indagação: quais capacidades substantivas devem ser implementadas para a eliminação do trabalho infantil na cadeia produtiva do açaí?

Para tanto, traça-se como objetivo geral apontar os instrumentos necessários para a eliminação dos fatores de indução e manutenção da ocorrência do trabalho infantil na cadeia produtiva a despeito da ilicitude da atividade. Elencam-se como objetivos específicos: a) apresentar a ocorrência do trabalho infantil na extração do açaí; b) identificar os fatores de risco para indução e permanência do trabalho infantil naquela atividade; c) expor o referencial teórico sobre capacidades e funcionamentos e; d) propor uma relação de capacidades, com os

3 Neste sentido, a Constituição da República Federal do Brasil - CRFB (BRASIL, 1988), a Consolidação das Leis do Trabalho - CLT (BRASIL, 1943) e o Estatuto da Criança e do Adolescente - ECA (BRASIL, 1990). 
respectivos instrumentos/estratégias para implementação voltados à solução do problema.

A hipótese a ser testada é que, a despeito da existência de uma lista geral de capacidades que deve ser implementada para todos, de forma indistinta, o contexto específico de determinada comunidade exige o estudo, o debate e a implementação de outras, adequadas ao perfil da comunidade e ao perfil das pessoas que ali vivem, a fim de garantir o real desenvolvimento físico, mental e social das crianças.

Quanto aos aspectos metodológicos, o estudo está estruturado, quanto à abordagem, em pesquisa qualitativa; quanto à natureza, revelou-se como pesquisa aplicada, com o intuito de gerar conhecimento para a aplicação prática; quanto aos objetivos, a pesquisa é tipo exploratória; quanto aos procedimentos, foi realizada pesquisa bibliográfica.

Além da introdução e considerações finais, o presente trabalho encontra-se dividido em três seções com a argumentação necessária à solução do problema de pesquisa que se apresenta. Na primeira seção, discorrer-se-á a respeito do trabalho infantil e sua existência na cadeia produtiva do açaí, com a apresentação dos motivos de indução e permanência. Na segunda seção, apresentar-se-á o referencial teórico a respeito de capacidades e funcionamentos. Na terceira seção, descrever-se-á as capacidades e funcionamentos, com métodos de implementação e verificação. Nas considerações finais, responder-se-á o problema de pesquisa.

\section{O TRABALHO INFANTIL NA ATIVIDADE DE EXTRAÇÃO DO AÇAÍ}

Pode ser considerado trabalho infantil aquele que é mental, fisicamente, social ou moralmente perigoso e prejudicial às crianças, interferindo na sua educação, quer privando-a da oportunidade de frequentar a escola, quer obrigando-a ao abandono de forma prematura, ou impondo-lhe combinar a frequência escolar com o trabalho excessivamente pesado, penoso, exaustivo e desgastante.

A propósito, a respeito do assunto, Brito Filho (2018, p. 137) expõe que:

(...) nessas condições, estudar é a possibilidade que fica negada, ou que, pelo menos, torna-se muito mais difícil, com evidentes prejuízos, presentes e futuros, para todos os que, em período em que deveriam ter todo o apoio necessário, encontram-se uma etapa à frente, executando tarefas que ainda não deveriam deles ser exigidas.

Em suas formas mais extremas, o trabalho infantil envolve crianças separadas de suas 
famílias, escravizadas, vivendo pelas ruas, com exposição a perigos e doenças graves. Contudo, isto não valida a presunção de que o trabalho realizado no âmbito familiar seria menos prejudicial que o realizado nas ruas, pois também não há garantia de que haverá proteção da criança no âmbito familiar. Para isso, basta citar, como exemplos, a exploração do trabalho infantil na atividade agrícola, uma das ocupações mais perigosas, bem como o trabalho doméstico.

A positivação dos direitos da criança, inclusive no texto constitucional, fundada na doutrina da proteção integral, demonstra o compromisso do Estado de garantir o pleno exercício de seus direitos, com a observância da característica especial de pessoa em desenvolvimento, retirando-a de toda e qualquer forma, ambiente ou situação que possam prejudicar seu crescimento físico e intelectual, bem como sua moral.

A despeito da proteção normativa, segundo o Instituto Peabiru (2016), a mão de obra infantil é utilizada na atividade de extração do fruto açaí, em virtude dos aspectos físicos, pois o indivíduo mais ágil, mais leve, consegue subir rapidamente e colher o necessário para o consumo da família. Contudo, em face do crescimento exponencial da demanda pelo vinho (polpa) de açaí, a coleta passou a atender não apenas ao consumo da própria família ou localidade, ou o limitado mercado regional, que consome o açaí fresco, in natura, para se transformar em uma cadeia de valor de interesse global, com envolvimento de novos atores (indústrias processadoras, atacadistas, varejistas e outros).

Segundo Marinho (2005), o processo de aprendizagem relativo à subida no açaizeiro inicia por volta de 6 a 7 anos, geralmente por crianças do sexo masculino, com incentivo e recebimento de instruções básicas dadas pelo pai como, por exemplo, não deixar a peconha sair dos pés e segurar bem a palmeira para evitar queda. Assinala que, aproximadamente dois anos após, a criança torna-se um ágil coletor, em virtude do aumento de sua força física e de seu peso, denotando uma habilidade invejável, vez que consegue subir em árvores mais finas, as quais não suportam o peso de um adulto. Por essas razões, assinala que não se verificou, durante sua pesquisa, nenhuma preocupação relativa às implicações que o uso intenso da mão de obra infantil pode acarretar às crianças.

Em pesquisa de campo, Ferreira e Koury (2020) assinalam que o cenário continua o mesmo, ou seja, as crianças continuam atuando na extração do açaí em virtude de suas condições físicas, que permitem agilidade na subida, especialmente nas árvores com caule frágil, bem como a passagem de uma árvore para outra. 
A extração do açaí é atividade complexa que não se resume à subida no açaizeiro. A gama de atividades que deve ser realizada pelo "peconheiro" antes da extração propriamente dita, representa a complexidade da atividade que exige destreza, força e conhecimento da realidade local, que envolve uma série de riscos, em virtude do ambiente onde é extraído e a forma como ocorre a extração e o deslocamento.

O exame dos fatores que contribuem para a ocorrência do trabalho infantil e garantem sua permanência dentro da estrutura de uma cadeia produtiva está vinculado à interação de diversas dimensões, das quais se destacam as pressões socioeconômicas suportadas pelos trabalhadores, a atuação governamental e o cumprimento efetivo da lei e sua fiscalização.

Assim, o trabalho infantil deve ser compreendido como um fenômeno estrutural e complexo que requer respostas globais em matéria de políticas públicas, pois, ao se adotar apenas um enfoque - a pobreza, por exemplo, ter-se-á uma visão bastante limitada sobre a sua eliminação, sujeitando-se ao sério risco de produzir violações em outras áreas, sem o alcance do objetivo final e real.

Dessa forma, pensar em eliminação do trabalho infantil representa pensar nos diversos e principais fatores de impulso e atração que permitem a sobrevivência dessa espécie de violação e exploração do ser humano.

\subsection{Fatores de Impulso}

Dentre os fatores que contribuem para a ocorrência do trabalho infantil, é possível elencar os seguintes:

A pobreza aumenta as chances das famílias incentivarem e permitirem o trabalho precoce de suas crianças para complementar a renda. Isto sugere que o trabalho infantil funciona como um amortecedor ou uma válvula de escape na ocorrência de crises no âmbito familiar. As crianças podem trabalhar como não remuneradas, como ajudantes na propriedade da própria família ou, ainda, auxiliar familiares em propriedades alheias. Relaciona-se ao caso, a ocorrência de superveniência de desemprego entre os jovens e os adultos pertencentes ao núcleo familiar, momento em que a criança passa a ser responsável também pela formação da renda familiar.

Segundo Arroyo (2015), devido à precarização da vida familiar, à escassez de trabalho e ao desemprego dos pais, as crianças são levadas a ser sujeitos ativos no trabalho, na 
composição da renda, para a sobrevivência pessoal e familiar. Assim, passam a experimentar o viver precário do seu coletivo familiar. Nesse contexto, revela-se o trabalho como um dos aprendizados mais precoces na vida de uma criança.

A educação pública gratuita e de qualidade é uma alternativa ao trabalho infantil. De outro lado, a falta de acesso às escolas e a má qualidade do ensino podem estimular as crianças ao trabalho infantil. Nota-se que as crianças residentes em áreas rurais têm dificuldades para ter acesso à escola, ou sequer o tem, seja em virtude dos longos deslocamentos e do custo para fazê-lo, seja em decorrência da própria inexistência de unidade escolar.

Além disso, embora seja possível a frequência escolar, a qualidade da educação oferecida é um fator importante na percepção das famílias sobre seu valor, em comparação com os benefícios de sua participação na geração de renda ou atividades domésticas.

Importante destacar, ainda, o impacto da privação da educação em relação às perspectivas do mercado de trabalho no ciclo de vida. Ou seja, as pessoas com baixos níveis de educação carecerão de competências e de poder de negociação necessários para obter um trabalho decente dentro da economia formal, o que as torna mais vulneráveis a violações de direitos humanos.

Por outro lado, o abandono escolar é explicado por várias razões, sejam elas relacionados com aspectos econômicos, culturais ou sociais ou mediadas pela influência do grupo de pares, dos pais ou outros familiares. Este fenômeno tem de ser analisado no quadro das relações que se estabelecem no interior do tecido social, as quais condicionam as realidades internas das escolas que os alunos abandonam (MELRO, 2015).

Por fim, é importante que a escola seja o local no qual as crianças possam debater os padrões de trabalho e as relações que as cercam, ou seja, exerçam o direito de conhecerem a realidade e a verdade do seu precário modo de sobreviver. Aumenta-se o dever político da escola de discutir com a classe pobre as causas de sua pobreza e os meios para combatê-la.

Geralmente, observa-se um círculo de pobreza, revelado pelo fato de os pais terem iniciado as atividades na colheita e não terem oportunidades próprias, de modo que podem não estar cientes do valor de educar seus filhos. Por essa razão, a falta de consciência da relação entre escolaridade e níveis de renda pode explicar por que as famílias subestimam o valor de enviar crianças para a escola. Ademais, isso pode ser corroborado pela qualidade da educação e pelas oportunidades de emprego disponíveis no local aos jovens que frequentaram 
a escola, que não é diferente das atividades realizadas pelos pais, ou seja, sem a oferta de postos de emprego com garantias mínimas e proteção social, frequentar a escola ou não é indiferente. Além disso, o trabalho infantil pode ser considerado culturalmente aceitável em certos contextos.

A existência de normas que garantem a reprodução cultural, passadas de geração em geração, vistas como forma de aprendizado, sem preocupação com o desenvolvimento da criança é marcante na sociedade investigada. As crianças que atuam precocemente na atividade de extração do açaí são elogiadas, tidas como crianças responsáveis, sendo incentivadas a tanto pelo grupamento social.

Entende-se que a redução e a eliminação do trabalho infantil deve iniciar a partir de uma mudança sociocultural, com o reconhecimento da importância da infância e da escolarização das crianças.

A ausência de perspectivas de emprego decente para jovens, após longo período de frequência escolar, representa um empecilho para que as famílias invistam na educação das crianças, devido à falta de oportunidades. Assim, as pessoas com menos de 18 anos são relegadas a trabalhos agrícolas perigosos devido à falta de alternativas.

Aliado a esse fato, é oportuno destacar o dilema que é ingressar no mercado de trabalho, para o qual, uma das exigências, é possuir diploma de conclusão do Ensino Médio, ou ao menos do Fundamental. A criança que foi condenada a trabalhar para sobreviver terá negado seu direito ao trabalho decente. Ou seja, condena-se desde cedo aquela criança que, por ter trabalhado e não ter tido tempo, a não ter um trabalho digno.

Há outros fatores socioeconômicos como a existência de problemas estruturais nas famílias. Muitas delas estão sob a direção de adolescentes que foram pais precocemente, ou ainda com significativa presença de violência doméstica e outras formas de violência, uso de drogas e o fato de o trabalho das crianças ser visto como preferível alternativa à ociosidade.

Identificados os principais fatores que impulsionam a existência de trabalho infantil na extração do açaí, passa-se ao exame dos fatores de permanência, ou seja, aqueles que asseguram a manutenção da criança na atividade laboral.

\subsection{Fatores de Permanência}

Dentre os fatores que contribuem para a permanência do trabalho infantil, é possível 
elencar os seguintes:

A necessidade de trabalho não qualificado em países com baixos níveis de mecanização pode aumentar a probabilidade de crianças que trabalham. Há evidências de que a incidência de trabalho infantil é inversamente proporcional ao progresso tecnológico. Isto porque a mecanização reduz a necessidade de pessoas não qualificadas no grupo de trabalho que as crianças representam.

A extração do açaí é uma atividade de trabalho intensivo, com alta incidência de trabalho infantil, especialmente em virtude dos baixos níveis de mecanização na extração do açaí nas várzeas. Os únicos objetos utilizados são a peconha e a faca, situação que permite que a criança, especialmente leve, consiga realizar a atividade sem a necessidade de um equipamento que lhe garanta segurança.

Os empregadores, com a intenção de reduzir seus custos trabalhistas, podem recrutar crianças como um custo efetivo alternativo para adultos. Embora as crianças demonstrem uma produtividade acentuada em comparação com o adulto, pois conseguem subir e descer da árvore com mais facilidade e rapidez, e tal produção pudesse ser um ponto positivo para a exigência de salários melhores, fato é que elas não são capazes de discutir o valor de sua remuneração, em virtude de sua exploração e vulnerabilidade no mercado de trabalho. Daí porque, embora sejam produtivas, as crianças não recebem o mesmo valor pago aos adultos que realizam as mesmas atividades.

As crianças nascidas em famílias proprietárias de propriedade rural, costumam trabalhar para seus pais, ajudando na extração do fruto. Nota-se que, em regra, as famílias não contratam empregados, no sentido legal, utilizando-se tão somente da mão de obra familiar. Tal situação demonstra a existência de trabalho familiar não remunerado, o que reduz o custo e repercute no aumento do lucro da família.

Em regra, os trabalhadores na extração do açaí não possuem vínculo de emprego formalizado (FERREIRA; KOURY, 2020). A alta probabilidade de informalidade dificulta a obtenção de uma imagem clara das condições de trabalho e abre caminho para a exploração infantil. Geralmente, a maioria das pessoas que trabalha na economia informal é exposta a condições de trabalho inadequadas e inseguras e com altos níveis de analfabetismo, baixa qualificação e oportunidades limitadas de formação, renda mais incerta, mais irregular e mais baixa do que aqueles que trabalham em economia formal, jornada de trabalho mais longa, sem gozo de direitos coletivos de negociação ou representação. 
A precarização condiciona a reprodução de toda a existência da classe trabalhadora, inclusive de seus filhos. Assim, ao condenar famílias ao emprego informal, revela-se a condenação de todos os seus membros a trabalhos informais para a garantia de sua sobrevivência. Mais uma vez, reitera-se que não é possível eliminar o trabalho na infância, sem antes eliminar o trabalho informal de sobrevivência a que são condenadas suas famílias.

De outro lado, a característica de sazonalidade da extração do fruto contribui para o processo de migração, ou seja, quando uma área fica sem açaí para ser extraído, a família, caso não possua outra fonte de renda que garanta aguardar o período do "inverno 4 ", fará o deslocamento de toda a unidade familiar para outro local, podendo ser no mesmo município ou em municípios mais próximos. O deslocamento da unidade familiar afeta diretamente as crianças, que deixam de frequentar a escola.

A despeito da existência de diversos regramentos sobre o trabalho infantil, tanto em âmbito nacional quanto internacional, a sua observância não é verificada no dia a dia da comunidade pesquisada.

De outro, a existência de leis protetivas não é suficiente se não for acompanhada da capacidade necessária para implementá-las, fiscalizar seu cumprimento e penalizar o infrator.

Especificamente na região amazônica, especialmente em áreas rurais e remotas, observa-se que o alto número de locais de trabalho a serem inspecionados excede os recursos disponíveis para a sua execução, o que resulta na falta de proteção dos trabalhadores, na impunidade de infratores e na concorrência desleal. Contudo, a efetivação de direitos possui custo social e é papel do Estado propiciar meios e instrumentos reais para se fazer a proteção da criança, fornecendo o aparato humano, técnico e instrumental necessário para as devidas visitas de fiscalização.

Embora seja possível estimar o número total de pessoas envolvidas no trabalho infantil, não é tarefa fácil determinar quantas delas participam da produção e do consumo vinculado às cadeias mundiais. É ainda mais difícil identificar, com precisão, o trabalho infantil e a relação das pessoas com as cadeias de consumo e determinar o alcance da violação dos direitos humanos.

Para garantir a rastreabilidade das origens do produto final, ou de suas partes, é necessário contar com dados estatísticos não apenas do mercado no qual se consome o

4 Período de grande intensidade pluviométrica (chuvas) na região. Geralmente, inicia no mês de novembro de um ano e encerra em maio do ano seguinte. 
produto, mas também de toda sua cadeia de produção, os quais não podem ser obtidos pelos métodos tradicionais de estatísticas nacionais.

Por outro lado, há ainda dificuldade de identificar informações sobre os trabalhadores que não estão localizados no nível mais visível da cadeia, como por exemplo, aqueles que estão nos seus níveis iniciais, atuando na extração do fruto, por exemplo.

Segundo Vilella (2015), está-se diante de formas de acumulação que se baseiam na exploração da mão de obra infantil em setores orientados para o mercado e à exportação, e não à subsistência. Por trás dos circuitos supostamente informais, esconde-se a integração de crianças à grande indústria na produção e na circulação de mercadorias.

Identifica-se a existência de diversos fatores, tanto de atração quanto de permanência do trabalho infantil na cadeia do açaí, que precisam ser compreendidos de forma interligada, permitindo a exata compreensão de que o problema social não será resolvido com o enfrentamento de apenas um dos fatores, sendo necessário atuar de forma organizada em face de todos eles.

Explicitada a cadeia produtiva do açaí, com apontamento dos fatores que impulsionam e daqueles que asseguram a permanência do trabalho infantil, passa-se agora ao exame do referencial sobre capacidades e funcionamentos.

\section{CAPACIDADES E FUNCIONAMENTOS}

Os seres humanos diferem quanto às suas características externas, circunstanciais, vivências em ambientes natural e social, fatores epidemiológicos da região e características pessoais, entre outras. Toda essa diversidade é importante para analisar a desigualdade. Além disso, as vantagens e as desvantagens atribuídas às pessoas, quando comparadas umas às outras, podem ser analisadas a partir de diversas variáveis, como, por exemplo, renda, riqueza, utilidade, recurso, liberdade, direito, qualidade de vida, e assim por diante.

Nesse cenário, Sen (2017) identifica a dificuldade de escolha de um campo específico para avaliação, sob o argumento de que a pluralidade de variáveis que podemos focalizar (as variáveis focais) para avaliar a desigualdade interpessoal faz com que seja necessário enfrentar, em um nível bem elementar, uma difícil decisão com relação ao espaço de avaliação, que compreende o conjunto das variáveis selecionadas para exame, cujo conteúdo é de suma importância para o exame da desigualdade. 
A existência de uma pluralidade de variáveis e a sua observância para o exame da desigualdade não torna a teoria sobre a qual se assenta desprovida de substância ou um conteúdo vazio. Sen (2017) defende que, mesmo antes da escolha de um espaço específico, o requisito geral da necessidade de valorar a igualdade em algum espaço que é visto como particularmente importante, não é uma exigência vazia. Ademais, a variedade de espaços nos quais a igualdade pode ser exigida reflete uma diversidade mais profunda, que é a dos diferentes diagnósticos dos objetos portadores de valor - visões diferentes sobre as noções apropriadas da vantagem individual nos contextos em questão.

Assim, busca-se apoio na ideia defendida por Sen (2017), para quem uma saída para a caracterização da liberdade é a análise da forma de conjuntos alternativos de realizações que temos o poder de realizar.

A análise da liberdade enquanto conjunto de realizações parte da ideia de avaliação da capacidade do bem-estar e da liberdade para buscar bem-estar, sendo a primeira compreendida em termos da qualidade do estado da pessoa. Ou seja, bem-estar representa viver em um conjunto de funcionamentos inter-relacionados, que compreendem estados e ações, com o objetivo de alcançar o objetivo pessoal do indivíduo.

Sen (2017) explica que os funcionamentos são constitutivos do estado de uma pessoa, e uma avaliação do bem-estar tem de assumir a forma de uma apreciação desses elementos constituintes. Destaca, ainda, que relacionada intimamente à noção de funcionamento está a de capacidade para realizar funcionamentos, a qual representa as várias combinações de funcionamentos que uma pessoa pode realizar.

Pontualmente, Sen (2017, p. 80) afirma que a "capacidade é, portanto, um conjunto de vetores de funcionamentos, refletindo a liberdade da pessoa para levar um tipo de vida ou outro", repercutindo, portanto, na relação que o conjunto capacitário reflete, no espaço de funcionamentos, a liberdade da pessoa para escolher dentre vidas possíveis.

Continuando a sua exposição, Sen (2017) trata da identificação de objetos-valor, e concebe o espaço de avaliação em termos de funcionamentos e capacidades para realizar funcionamentos. Dentro desse contexto, há elementos de verdadeira escolha quanto aos funcionamentos a serem incluídos na lista de funcionamentos relevantes e de capacidades importantes. O formato geral de ações e de estados permite que realizações adicionais sejam definidas e incluídas. Alguns funcionamentos podem ser fáceis de descrever, mas sem maior interesse na maioria dos contextos. Não há como escapar do problema da avaliação ao 
selecionar uma classe de funcionamentos - e ao descrever as capacidades correspondentes. $\mathrm{O}$ foco tem de estar relacionado com os interesses e os valores subjacentes, em termos dos quais alguns funcionamentos definíveis podem ser importantes e outros, bastantes triviais e negligenciáveis.

Na teoria de justiça distributiva de Sen para a avaliação do bem-estar os objetos-valor são os funcionamentos e as capacidades. A capacidade é principalmente um reflexo da liberdade para realizar funcionamentos valiosos. Ela se concentra diretamente sobre a liberdade como tal e não sobre os meios para a realizar, e identifica as alternativas reais que os indivíduos possuem. Neste sentido, ela pode ser lida como um reflexo da liberdade substantiva, de modo que na medida em que os funcionamentos são constitutivos do bemestar, a capacidade representa a liberdade de uma pessoa para realizar bem-estar.

Robeyns (2003) pontua com exatidão a diferença entre um funcionamento e uma capacidade por meio da metáfora de que a diferença se assemelha à diferença entre uma conquista e a liberdade de conseguir algo, ou entre um resultado e uma oportunidade. Ou seja, capacidades são possíveis funções das pessoas, enquanto que funcionamentos são realizações. Todos os recursos juntos correspondem à liberdade geral de levar a vida que uma pessoa tem motivos para valorizar.

Nota-se, portanto, a existência de uma teoria que analisa a desigualdade e, por consequência, a justiça distributiva em uma dada sociedade, a partir das capacidades de que dispõem os seus membros para fazer e buscar fazer aquilo que entendem como objetivos de vida. O foco nas capacidades tem a importância de deslocar a análise do referencial da renda e riqueza, permitindo a análise de outras variáveis relacionadas à própria diversidade humana, que não pode ser ignorada se, efetivamente, o objetivo é analisar, no mundo fático, a existência de desigualdade e de injustiça.

De outro lado, a teoria exposta por Sen não garante respostas completas, pois não se consubstancia em uma fórmula que prescreve como medir a desigualdade. Nota-se que a abordagem da capacidade serve para deslocar o espaço focal para o exame dos recursos. Contudo, não informa quais recursos devem ser considerados. É certo que, partindo da premissa de capacidades, torna-se possível escolher os recursos relevantes. Contudo, a teoria de Sen não apresenta uma visão de mundo particular. Ao contrário, trata de formas genéricas de garantia de capacidades e funcionamentos para a escolha do melhor fim possível, dentre as opções disponíveis. 
A despeito disso, há valiosas vantagens em utilizar a teoria acima. A primeira delas é que as capacidades e os funcionamentos são propriedades de indivíduos. Esse dado representa que cada pessoa será considerada em si mesma. Como exemplo, para o exame da desigualdade, a criança poderá ser objeto de investigação e não a sua família, em conjunto, sendo possível, portanto, fazer a correta análise dos indivíduos que sofrem privações dentro de um contexto mais amplo que pode até não sofrer tal privação, por exemplo. Reconhece-se o caráter individual do sujeito. Ao mesmo tempo, a abordagem não é, em sua essência, individualista, nem pressupõe que as capacidades e os funcionamentos estão desprendidos da preocupação com os outros. Ou seja, a análise não é individualista, mas o indivíduo, com todas as suas peculiaridades, não é desconsiderado.

A segunda vantagem é que a análise das capacidades não se limita ao exame do mercado, mas considera os indivíduos e suas ações no mercado e fora dele. Ou seja, há uma dimensão não mercadológica que será analisada para o exame do bem-estar, que não o seria sob o prisma da investigação sobre renda ou riqueza.

Por fim, como fica bastante claro nas assertivas de Sen (2017), há abordagem explícita sobre a diversidade humana, nos traços de idade, etnia, gênero, bem como análise dos vulneráveis. Tal concepção é importante pois afasta a ideia de que todas as pessoas são iguais e possuem a mesma capacidade para conversão em funcionamentos.

A despeito das vantagens identificadas na teoria que enfoca o exame das capacidades há um ponto crítico. É que a teoria sustenta que, no exame da desigualdade, é necessário focar nas capacidades. Contudo, toda avaliação é pautada com fundamento em uma teoria social, com fatores individuais, sociais e ambientais diversos, mas que produzirão resultados bastante divergentes se, a cada exame de capacidades, for adotada uma teoria social distinta. Pode-se dizer, inclusive, que a própria capacidade de avaliação poderá ser maculada se, por exemplo, for adotada uma concepção que nega a ocorrência de prejuízo à criança que labora precocemente.

Em virtude de tal diagnóstico, para a aplicação da abordagem de Sen ao objeto de estudo, faz-se necessária a especificação de algumas diretrizes, a saber: i) a seleção de quais recursos são importantes para avaliar a desigualdade sofrida pelas crianças na cadeia do açaí, que devem compor uma lista; ii) a decisão sobre o que deve ser analisado naquela desigualdade, se a existência de capacidades ou funcionamentos, ou ambos; e iii) como ponderar, dentro de cada contexto específico, as diferentes capacidades e funcionamentos. 
Em virtude das assertivas acima, sabendo que Sen não responde quais são os recursos relevantes para avaliar a desigualdade, pois, em sua teoria, não se ocupou em propor uma lista para defini-los, mesmo após a sugestão de Nussbaum (2013, p. 204), que registra "[...] sugeri, em outro lugar, que a relutância de Sen em elaborar tal lista dificulta seu projeto de usar as capacidades para definir uma teoria de justiça social", passa-se ao exame da lista de capacidades proposta por Martha Nussbaum.

\section{CAPACIDAdES SUBSTANTIVAS ESPECÍficAs PARA ELIMINAÇÃo DO TRABALHO INFANTIL}

A partir das premissas acima, entende-se necessário apresentar determinadas capacidades para que as crianças sejam excluídas da exploração do trabalho prematuramente.

A primeira delas é assegurar a inviolabilidade do direito à vida das crianças. A principiologia é assegurar juridicamente a sobrevivência de todos os indivíduos na fase da infância e da adolescência.

Como instrumento para a satisfação da capacidade, aponta-se a necessidade de controle severo da mortalidade infantil, por meio do acompanhamento da gestante, com esclarecimentos sobre os cuidados necessários com a criança, inclusive informações relativas à alimentação adequada e à vacinação periódica. Pode-se valer, para o caso, de profissionais que realizem visitas periódicas às famílias, especialmente àquelas que não disponham de recursos financeiros para o deslocamento ou que apresentem certa desvantagem para fazê-lo, como, por exemplo, gravidez de risco.

Outro instrumento de grande relevância é a existência de serviço público de saúde adequado, inclusive na esfera preventiva, de caráter permanente e próximo da comunidade, a fim de que ela possa se socorrer em casos de acidentes, especialmente aqueles ocorridos na extração do açaí, que exigem rápida atuação.

A fim de acompanhar e medir o desenvolvimento da capacidade, pode-se utilizar índices sobre a taxa de mortalidade infantil, sobre a expectativa de vida, sobre o acompanhamento das gestantes no período do pré-natal, sobre o números de famílias identificada em situação de agravada vulnerabilidade, que exija uma atuação diferenciada, sobre a quantidade de postos de saúde disponíveis à população, considerando um referencial para estabelecer o número adequado à quantidade de população atendida, por área específica, 
pois não é suficiente constar a existência de unidades de saúde em determinado município se, para o deslocamento até elas, o esforço é alto e, às vezes, até impossível, com provável comprometimento do direito à vida.

Por fim, é imprescindível a criação de um índice que retrate a quantidade de crianças envolvidas especificamente na atividade de extração do açaí, com especificação sobre a quantidade de acidentes ocorridos, o número de horas trabalhadas, dentre outras características, a fim de tornar visível essa realidade e permitir o planejamento específico para conter essa espécie de exploração.

Segue-se com o apontamento da capacidade saúde, que decorre do dever de cuidado com a criança, que deve gozar de boa alimentação e viver em lugar adequado, que permita que o seu desenvolvimento ocorra dentro dos padrões de normalidade.

A capacidade pode ser satisfeita com a implementação de programa de acompanhamento da alimentação infantil, com a orientação dos pais sobre os nutrientes necessários ao desenvolvimento da criança e as consequências de uma alimentação escassa. Ademais, em face do princípio da prioridade absoluta, que assegura às crianças a prioridade de atendimento, tratamento e consideração, entende-se que o Poder Público deve prover, às pessoas carentes, o fornecimento de gêneros alimentícios básicos, por meio de repasses, ou ainda pela isenção de imposto sobre produtos básicos, o que, por estar relacionado à prevenção de doenças, poderá repercutir na diminuição dos custos com a saúde pública. Por fim, o Poder Público deverá planejar e implementar programas visando assegurar moradia digna e decente a todos, por meio de financiamentos com juros reduzidos e/ou pela construção de casas populares.

A capacidade pode ser medida por meio da implementação de indicadores sobre o crescimento infantil e sobre a quantidade de famílias em situação de vulnerabilidade, que exigem uma atenção especial do Estado, o qual servirá de norte para a adoção de políticas públicas de repasse de renda e moradia digna, as quais, por sua vez, poderão ser medidas por índices sobre a quantidade de famílias cadastradas em programas específicos sobre a questão.

Nussbaum (2013) apresenta a capacidade integridade física que consiste na capacidade de se movimentar livremente de um lugar a outro; de estar protegido contra ataques de violência, inclusive agressões sexuais e violência doméstica; de dispor de oportunidade para satisfação sexual e para a escolha em questões de reprodução. Para fins do presente estudo, entende-se necessário ampliar o alcance da citada capacidade para tratá-la como integridade 
pessoal, a fim de abranger tanto a integridade física, quanto a psíquica, esta última relacionada diretamente aos direitos da personalidade do indivíduo. Assim, a integridade pessoal da criança passa a ser tratada sob um aspecto amplo, com o fim de assegurar proteção em face de diversas espécies de riscos.

Justifica-se a necessidade de implementação da capacidade integridade pessoal, a fim de garantir os direitos de liberdade à criança, com proteção adequada, retirando-a da exposição aos riscos existentes na cadeia produtiva.

Como instrumentos de implementação, elencam-se a retirada da criança do trabalho de extração do açaí e a atuação incisiva dos Conselhos Tutelares, bem como da própria comunidade e dos seus responsáveis, a fim de evitar a exposição a situações de vulnerabilidade.

Para medir o alcance da capacidade, aponta-se a utilização de indicadores sobre o número de acidentes sofridos pela criança, com a completa discriminação dos locais de ocorrência, a atividade que estava sendo desenvolvida e as partes do corpo afetadas. Além disso, pode-se utilizar índice para medir a quantidade de crianças que participam da composição da renda familiar. Por fim, é imprescindível haver o indicador sobre a quantidade de violências praticadas contra a criança, separadas por espécie, como, por exemplo, sexual, doméstica, dentre outras.

A capacidade sentidos, a imaginação, o pensamento diz respeito a ser capaz de fazer coisas de um modo verdadeiramente humano, informado e cultivado por uma educação adequada, incluindo, sem limitações, a alfabetização e o treinamento matemático e científico básico. Além disso, inclui a ideia de ser capaz de usar a própria mente de modo protegido por garantias de liberdade de expressão, com respeito tanto à expressão política quanto artística e à liberdade de exercício religioso, bem como ser capaz de ter experiências prazerosas e evitar dores não benéficas (NUSSBAUM, 2013).

Justifica-se que essa capacidade deve figurar na lista em virtude das consequências do trabalho infantil na vida e reprodução das crianças, as quais, em virtude da privação de tempo, não conseguem se dedicar de forma adequada ao aprendizado e, tampouco, à atividade criativa. As pessoas em privações permanentes adaptam-se ao seu estilo de vida, parecendo que estão confortáveis com determinada situação, quando, na verdade, estão apenas conformadas em face de um objetivo tido por elas como inatingível.

Entende-se que a capacidade pode ser satisfeita por meio da retirada da criança da 
atividade de extração do açaí, bem como por meio de educação adequada, incluindo, sem limitações, a alfabetização e o treinamento matemático e científico básicos.

Com o objetivo de medir o desenvolvimento, elenca-se a utilização dos índices sobre a taxa de frequência escolar, taxa de alfabetização, exames para apuração do aprendizado, índice sobre o desenvolvimento de atividade lúdicas na escola e a respectiva participação das crianças, dentre outros.

A capacidade lazer é tida como ser capaz de rir, brincar, gozar de atividades recreativas (NUSSBAUM, 2013). No cenário estudado, identifica-se que o custo da oportunidade para brincar é muito alto para famílias em situação de pobreza, que consideram as crianças como um recurso econômico de complementação da renda. Assim, a capacidade lazer está comprometida em virtude da atuação na colheita do fruto em um turno do dia e a frequência escolar, no outro. Em virtude da exaustão advinda da colheita do fruto, normalmente, as crianças estão fatigadas tanto para frequentar a escola quanto para a prática do lazer. Assim, torna-se imprescindível a retirada da criança daquela atividade desgastante.

Nesse contexto, Brito Filho (2018, p. 138) destaca que "não é só o tempo necessário para o estudo que está sonegado, mas também o de outras atividades, igualmente importantes, como o lazer, o descanso, o horários para as refeições etc."

Como instrumento para medir a implementação da capacidade, apresenta-se o uso de índice de frequência escolar, a fim de identificar se a criança está, de fato, participando da vida escolar, na qual, por certo, haverá espaço para o lazer. Além disso, pode-se utilizar também o indíce citado na capacidade anterior relativo à medição de existência do trabalho infantil.

Nota-se que, quanto ao primeiro índice, haverá uma relação diretamente proporcional com a respectiva capacidade, ou seja, quanto maior o índice de frequência escolar, maior será a probabilidade da criança estar fora da atividade de extração do açaí e conseguir brincar. De outro lado, sobre o índice relativo à existência do trabalho infantil, a relação é inversamente proporcional, ou seja, quanto maior for este índice, menor será o desenvolvimento da capacidade, em virtude da privação sofrida pela criança.

A capacidade educação compulsória de qualidade é entendida como obrigatoriedade de matrícula e frequência, especificamente para crianças, é justificada tanto pela imaturidade cognitiva das crianças quanto pela importância dessa funcionalidade para o desenvolvimento posterior das capacidades adultas (NUSSBAUM, 2013). 
Destaca-se que a melhoria do acesso e da qualidade escolar devem funcionar como estímulos às famílias, a fim de que possam compreender que investir na educação das crianças apresenta um rendimento maior do que colocá-las para trabalhar.

Assim, por considerar que o trabalho infantil representa um dos principais obstáculos de acesso ao direito à educação, tem-se como imprescindível que sua adoção seja compulsória às crianças.

Além disso, entende-se ser necessário reduzir os custos diretos relacionados à escolaridade, a exemplo de deslocamentos na zona rural, por meio da implantação de escolas na própria comunidade e do oferecimento de transporte escolar gratuito; fornecer alimentação adequada, melhorar a própria qualidade do ensino, inclusive com abordagens sobre a dinâmica produtiva local e as condições de trabalho e violência; contratar professores formados e, de preferência, da própria comunidade; promover a participação dos pais na vida escolar de seus filhos, por meio de reuniões periódicas, contatos e visitas; ampliar o horário escolar e as atividades desenvolvidas fora daquele horário como alternativa ao trabalho infantil.

A fim de mensurar o nível de implementação da capacidade em exame, entende-se ser útil a utilização de indicadores relacionados ao índices de alfabetização, de matrícula, de frequência escolar e da própria escolaridade.

A capacidade hipervulnerabilidade e respeito relaciona-se a ser reconhecido como indivíduo em fase de desenvolvimento, com características próprias, distintas das dos adultos, em situação de hipervulnerabilidade na comunidade local em virtude de sua exposição a riscos diversos, relacionados, principalmente, à sua imaturidade física e mental, que as privam de realizar as melhores escolhas para sua própria vida, a exigir, portanto, atuação positiva do Estado e da própria sociedade.

Justifica-se a sua inclusão na lista em virtude da situação de hipervulnerabilidade das crianças na comunidade investigada, as quais, conforme exposto acima, recebem recursos financeiros diretamente e os utilizam para o consumo de bebidas alcoólicas e outras drogas. Além disso, o próprio trabalho infantil corrobora para a existência de total desrespeito à criança.

Como ferramentas para a implementação da referida capacidade, sugere-se a incorporação das preocupações relativas ao trabalho infantil em todas as ações desenvolvidas nas atividade privadas e naquelas desenvolvidas pelo Estado, seja no âmbito federal, estadual 
ou municipal, a fim de tratar o trabalho infantil em consonância com as demais atuações, haja vista que, em grande parte, é consequência de escolhas políticas e de políticas públicas que tratavam de matéria diversas e não se ocuparam de pensar nas consequências que poderiam enfrentar as crianças da região.

Percebe-se, portanto, que as ações privadas e as políticas públicas devem ser pensadas a fim de evitar que uma de suas consequências seja a exploração do trabalho infantil. Nesse cenário, deve-se garantir prioridade ao problema do trabalho infantil nas atuações públicoprivadas. Como corolário, há necessidade de atualização das ferramentas de avaliação dos riscos do trabalho infantil e de desenho de modelos de intervenção rápida quando verificada sua ocorrência, no curso de implantação de alguma ação governamental ou privada.

A fim de medir a implementação da atividade, pode-se utilizar da criação de um índice que identifique a preocupação, das empresas e do governo, em incluir a temática sobre o trabalho infantil nos seus planejamentos empresarias e governamentais, identificando-as como entidades parceiras da criança, por exemplo. Alinhado a isso, no mesmo planejamento, poderia constar a exigência de contratação de empresas que não utilizem a mão de obra infantil em suas atividades. A adoção de uma exigência como esta, uma espécie de selo social, poderia atestar a preocupação do empreendimento com a temática, inclusive, gerar resultados de replicação de sua conduta, alinhada à ideia de sustentabilidade social.

A capacidade ocupação decente para jovens está relacionada a ser capaz, a partir da idade para trabalhar, de ocupar postos de trabalho que garantam o respeito à dignidade humana, com remuneração adequada, suficiente para o exercício e o gozo de seus direitos, em local adequado, sem riscos acima dos limites de tolerância, assegurando a possibilidade de pleno desempenho de suas faculdades.

Entende-se necessária a existência de tal capacidade, em face de ser uma alternativa ao trabalho exaustivo de extração do açaí.

Além disso, o trabalho decente para as pessoas em idade para trabalhar representa ponto crucial para conter a pobreza familiar e, por consequência, o trabalho infantil, conforme visto quando da análise dos fatores de atração. Assim, pode-se dizer que o aumento de postos de trabalho decente repercute na probabilidade das famílias necessitarem do trabalho infantil para a complementação da renda.

De outro lado, a capacitação citada serviria ainda para a criança reconhecer em alguém próximo, um padrão de comportamento que não seja aquele voltado ao consumo de álcool, 
pelo reconhecimento no outro, sem a necessidade de força ou pressão exterior.

A capacidade pode ser medida por meio da identificação do índice de postos de trabalho criados na região, correlacionado-o com o índice de admissão de jovens ao emprego. Além disso, torna-se necessária a existência de fiscalização dos referidos locais de trabalho, a fim de averiguar a existência de trabalho decente, o que pode ser aferido pelo teor das citadas fiscalizações.

A capacidade proteção social refere-se a ser protegido em virtude de privações decorrentes da pobreza extrema, vez que esta exerce influência direta sobre o trabalho infantil, tido como recurso para a sobrevivência familiar e da própria criança.

Dessa forma, entende-se necessária a implementação da citada capacidade, a qual incluirá medidas que proporcionem renda e segurança às famílias, por meio de transferências de renda; introdução e ampliação dos sistemas de alimentação nas escolas, a fim de reduzir a insegurança alimentar e ser um incentivo adicional à frequência escolar, alinhada ao fato de que a alimentação pode contribuir para a melhoria da concentração e do rendimento dos alunos, com o aproveitamento do tempo na aula; ampliação da proteção social às pessoas com certas desvantagens, o que inclui prestações em virtude de incapacidades (doenças); garantia de remuneração aos idosos, por meio de aposentadorias que ajudem a compensar as desvantagens decorrentes de faixa etária, com garantia aos seus dependentes; proteção contra o desemprego; introdução de sistemas de microcréditos às famílias vulneráveis, a fim de facilitar o ingresso no mercado financeiro, dentre outros. Com base em tais instrumentos, tenta-se evitar que a pobreza extrema incentive o trabalho precoce.

Para medir a implementação da citada capacidade, pode-se utilizar como indicadores a análise do sistema de aposentadorias e benefícios previdenciários, os regramentos sobre proteção ao desemprego e fornecimento de microcrédito às pessoas de baixa renda, bem como os índices relativos aos programas de transferência de renda à população envolvida.

Identifica-se, para cada capacidade, o fornecimento de um rol de ações/ estratégias na tentativa de tornar possível sua implementação. Ao lado disso, consta uma série de indicadores necessários para o acompanhamento das citadas ações, a fim de permitir identificar eventual ajuste.

Percebe-se que muitas capacidades necessitam, para sua implementação, que a criança seja retirada da atividade de extração do açaí, o mais breve possível, sob pena de perpetuação de um estado de completa violação a direitos básicos, com repercussões no gozo de suas 
liberdades fundamentais. Assim, os instrumentos apontados relacionam-se também à própria erradicação do trabalho infantil.

\section{CONSIDERAÇÕES FINAIS}

A partir da observação da atividade de extração do açaí na ilha de Marajó, identificouse a utilização da mão de obra infantil, como decorrência da expressão cultural daquela comunidade, aliada a fatores de impulsionamento, dentre os quais, destaca-se a pobreza, que favorece a utilização da criança como sujeito ativo de complementação da renda familiar.

O desenvolvimento do trabalho em idade precoce acarreta uma séria de privações imediatas à criança, como a ausência de lazer, frequência escolar, além de outras que serão reproduzidas na fase adulta, resultando em dificuldades, por exemplo, de ser alocada em emprego formal. Tal constatação parte do referencial teórico sobre as capacidades, como liberdades para fazer escolhas que propiciem bem-estar, ou seja, liberdade para a produção de funcionamentos, em um contexto de possibilidade de escolhas.

Discorreu-se sobre as capacidades em seu aspecto amplo, refinando-as para o exame de uma lista específica, que contemplasse capacidades inerentes à determinado grupamento humano, considerado em todas as suas particularidades. Assim, foi possível encontrar a resposta ao problema de pesquisa do presente trabalho.

Responde-se que as capacidades necessárias para assegurar o desenvolvimento físico, mental, social e cultural das crianças que atuam na extração do açaí, na Ilha de Marajó são: vida, saúde, integridade pessoal, sentidos, imaginação e pensamento, emoções, interação social, lazer, educação compulsória de qualidade, hipervulnerabilidade e respeito, conscientização contra o uso de drogas, desenvolvimento cultural, ocupação decente para jovens e, por fim, proteção social.

A respeito de cada capacidade foram apresentadas as razões que justificaram a sua escolha, o que garante transparência necessária para permitir o diálogo/debate acadêmico e comunitário sobre as eventuais alterações do cenário social, que possam exigir a substituição/ alteração/manutenção de determinada capacidade.

Além disso, foram apresentados diversos instrumentos que poderão ser úteis na tarefa de efetivar as citadas capacidades, ao lado de indicadores específicos para cada uma deles, no 
sentindo de acompanhar e mensurar as implementações.

A existência de uma lista de capacidades específicas permite, além do acompanhamento, a cobrança de ações dos poderes públicos e de toda a sociedade a fim de garantir, de fato, o princípio constitucional de prioridade de atendimento às crianças.

\section{REFERÊNCIAS}

ARROYO, Miguel G. A infância repõe o trabalho na agenda pedagógica. In: ARROYO, Miguel G; VIELLA, Maria dos Anjos; SILVA, Maurício Roberto da. (orgs.). Trabalho Infância: exercício tensos de ser criança, haverá espaço na agenda pedagógica? Petrópolis, RJ: Vozes, 2015.

BRASIL. [Constituição (1988)]. Constituição da República Federativa do Brasil. Brasília, DF: Presidência da República. Disponível em:

http://www.planalto.gov.br/ccivil_03/constituicao/constituicaocompilado.htm. Acesso em: 28 jan. 2019.

BRASIL. Decreto-Lei $\mathbf{n}^{\mathbf{0}} \mathbf{. 5 . 4 5 2}$, de $\mathbf{1}^{\circ}$ de maio de 1943. Aprova a Consolidação das Leis do Trabalho. Rio de Janeiro, RJ: Presidência da República. Disponível em: http://www.planalto.gov.br/ccivil 03/decreto-lei/del5452.htm. Acesso em: 18 jan. 2020.

BRASIL. Lei $\mathbf{n}^{\mathbf{0}}$. 8.069, de 13 de julho de 1990. Dispõe sobre o Estatuto da Criança e do Adolescente e dá outras providências. Brasília, DF: Presidência da República. Disponível em: http://www.planalto.gov.br/ccivil_03/leis/18069.htm. Acesso em: 18 jan. 2020.

BRITO FILHO, José Cláudio Monteiro de. Trabalho decente: análise jurídica da exploração do trabalho - trabalho escravo e outras formas de trabalho indigno. $5^{\text {a }}$ ed. São Paulo: LTr, 2018.

FERREIRA, Otávio Bruno da Silva; KOURY, Suzy Elizaneth Cavalcante. O açaí na Amazônia e o trabalho infantil: diálogo intercultural, hipervulnerabilidade e desenvolvimento regional. Rio de Janeiro: Lumen Juris, 2020.

INSTITUTO BRASILEIRO DE GEOGRAFIA E ESTATÍSTICA (Brasil). Pesquisa Nacional por Amostra de Domicílios Contínua - PNAD Contínua: Trabalho Infantil 2016. Brasília, DF: IBGE, 2017. Disponível em: https://biblioteca.ibge.gov.br/visualizacao/livros/liv101388_informativo.pdf. Acesso: em 03 jan. 2020.

INSTITUTO PEABIRU. "O Peconheiro": Diagnóstico das condições de trabalho do extrativista de açaí. Belém, Instituto Peabiru, 2016. Disponível em: https://institutopeabiru.files.wordpress.com/2017/09/160915-o-peconheiro-diagnosticoacai.pdf. Acesso em 05 jan. 2020. 
MARINHO, José Antônio Magalhães. Dinâmica das relações socioeconômicas e ecológicas no extrativismo do açaí: o caso do médio rio pracuúba, São Sebastião da Boa Vista, Marajó (PA). 2005. Dissertação (Mestrado em Planejamento do Desenvolvimento) - Núcleo de Altos Estudos da Amazônia - NAEA, Universidade Federal do Pará, Belém, 2005.

Disponível em: https://docplayer.com.br/50711579-Jose-antonio-magalhaes-marinho.html. Acesso em: 18 jan. 2020.

MELRO, Ana; TOMÁS, Catarina. A infância na indústria do entretenimento. In: ARROYO, Miguel G; VIELLA, Maria dos Anjos; SILVA, Maurício Roberto da. (orgs.). Trabalho Infância: exercício tensos de ser criança, haverá espaço na agenda pedagógica? Petrópolis, RJ: Vozes, 2015.

NUSSBAUM, Martha C. Fronteiras da Justiça: deficiência, nacionalidade, pertencimento à espécie. Trad. por Susana de Castro. São Paulo: Editora WMF Martins Fontes, 2013.

ROBEYNS, Ingrid. Sen's Capability Approach and gender Inequality: selecting relevant capabilities. Journal Feminist Economics, v. 9, p. 61-92, 2003. DOI:

10.1080/1354570022000078024. Disponível em: http://www.tandf.co.uk/journals. Acesso em: 02 jan. 2020.

SEN, Amartya Kumar. Desigualdade reexaminada. Traduzido por Ricardo Doninelli Mendes. $4^{\mathrm{a}}$ ed. Rio de Janeiro: Record, 2017.

VILELLA, Maria dos Anjos Lopes. A infância na indústria do entretenimento. In: ARROYO, Miguel G; VILELLA, Maria dos Anjos; SILVA, Maurício Roberto da. (orgs.). Trabalho Infância: exercício tensos de ser criança, haverá espaço na agenda pedagógica? Petrópolis, RJ: Vozes, 2015. 